\title{
COUNTING OF WBCs AND RBCs FROM BLOOD IMAGES USING GRAY THRESHOLDING
}

\author{
Pooja R. Patil ${ }^{1}$, G.S. Sable ${ }^{2}$, Gauri Anandgaonkar ${ }^{3}$ \\ ${ }^{1}$ Research scholar, Electronics, SPWEC, Aurangabad, Maharashtra, India \\ ${ }^{2}$ Principal, Electronics, SPWEC, Aurangabad, Maharashtra, India \\ ${ }^{3}$ Research scholar, Electronics, SPWEC, Aurangabad, Maharashtra, India
}

\begin{abstract}
Fast and cost-effective production of blood cell count reports are of paramount importance in the healthcare industry. In the market there are various systems for the automatic quantification of blood cells that allow counting the number of different types of cells within the blood smear. The traditional method of manual counting under a microscope yields inaccurate results and put an intolerable amount of stress to medical laboratory technicians. Due to high vulnerability in human error and large time consumption, better and more effective image processing software is needed. As a solution to this problem, this project proposes an image processing technique for counting the number of blood cells. The main goal of this work is the analysis and processing of a microscopic image, in order to provide an automated procedure to support the medical activity. In this project, the WBCs and RBCs are counted by using the gray thresholding algorithm computing with the manual method. This means that, the number of WBCs and $R B C s$ are counted from the five blood images. This procedure is done because in manual counting method, the cells are counted from the five squares. After counting the number of WBCs and RBCs from these five squares, these counts are then applied to the formula to count the normalized count. So, this same procedure is done to calculate the number of WBCs and RBCs in this project. The use of image processing help in improving the image quality and analysis approach from different application. It improves the effectiveness of the analysis in term of accuracy, time consuming and so on.
\end{abstract}

Keywords: White blood cells, Red blood cells, Manual method and Gray thresholding.

\section{INTRODUCTION}

Blood is a connective tissue consisting of cells suspended in plasma. From the identification of blood disorders, it can lead to classification of certain diseases related to blood. This project describes a preliminary study of developing a detection of blood cell count using microscopic blood sample images. Analyzing through images is very important as from images, diseases can be detected and diagnosed at earlier stage. From there, further actions like controlling, monitoring and prevention of diseases can be done. Blood's major functions are to transport various agents such as oxygen, carbon dioxide, nutrients, wastes, and hormones. Blood cells are composed of erythrocytes (red blood cells, RBCs), leukocytes (white blood cells, WBCs) and thrombocytes (platelets). The most abundant small reddish cells are erythrocytes and called red blood cell. An erythrocyte is a discoid cell with a thick rim and a thin sunken center. RBCs' two principal functions are to move oxygen from lung to tissues elsewhere and transport carbon dioxide from tissues to the lung. Where, the Leukocytes or white blood cells are part of the immune system.

\subsection{White Blood Cells}

White blood cells contain the immune cells that attack and remove viruses and bacteria in a person's body. Low WBC counts may indicate that a person is in danger of infection. High WBC counts might indicate an existing infection, tissue damage, or leukemia. Typical levels are 4,000-10,800 cells per microliter of a person's blood. In the manual WBC count, 50 $\mu \mathrm{l}$ of blood is mixed together with $950 \mu$ dilution solution. This constitutes a dilution of 1:20. The RBCs will be lysed (i.e. cells are destroyed by bursting), and the WBC nucleus is stained. The counting chamber is immediately filled after mixing. After 2 minutes, the MLT begins counting the WBCs in the 4 large squares. Calculation of the WBC count is achieved by following the formula below using these factors: i. The number of WBCs counted in the big squares

ii. The dilution of the cell solution

iii. The number of counted big squares

iv. The volume above a big square

WBC's $/ \mu 1=$

No of counted WBC's $\times$ dilution

No.of counted squares $\times$ volume above one big square

\subsection{Red Blood Cells}

Red blood cells carry oxygen from a person's lungs to the rest of their body. A depletion of red blood cells may lead to anemia. Anemia results in dizziness, fatigue, or even more 
serious symptoms if it is remain untreated. Red blood cell indices provide information about the size and hemoglobin content of the red cells. They are useful in differentiating types of anemia. Typical red blood cell count (RBC) levels are:

$\checkmark \quad 4.2$ to 5.4 million cells per microliter for women

$\checkmark \quad 2.6$ to 4.8 million cells per microliter for children

$\checkmark \quad 4.5$ to 6.2 million cells per microliter of blood for men.

In a manual RBC count, $10 \mu \mathrm{l}$ of blood is diluted in $1990 \mu \mathrm{l}$ of dilution solution. This results in a dilution of 1:200. This suspension is usually well-mixed and be immediately placed into the counting chamber. After approximately 3 minutes, the RBCs will have settled, and the MLT begins counting the RBCs in 80 small squares. The calculation is achieved by following the formula below using these factors:

i. The number of RBCs counted in the small squares

ii. The dilution of the cell solution

iii. The number of counted small squares

iv. The volume above one small square

$\mathrm{RBC}$ 's $/ \mu \mathrm{l}=$

No. of counted RBC's $\times$ dilution

No.of counted squares $X$ volume above one small square

\section{PROPOSED METHODLOGY}

With the help of the above block diagram, we are going to find out the WBCs and RBCs from the blood sample image taken from the hospital. This procedure is done to count the blood cells from blood sample image of 15 patients.

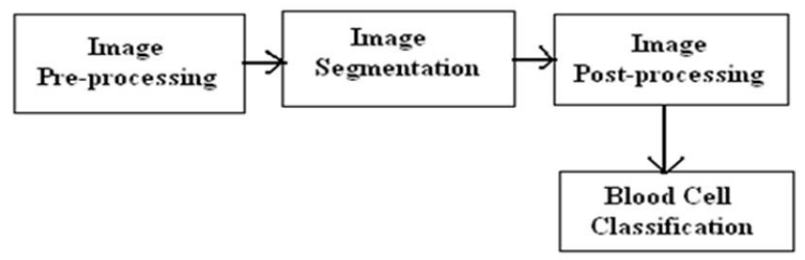

Fig-1: Steps for the process of blood cell classification.

In this project, our aim is to calculate the count of WBCs and RBCs from the microscopic blood images, to compute the results with the manual method. Even today, if the automatic cell counter counts some extra ordinary number of cells, the doctors count the cells manually to detect the abnormal cells. The flowchart of my project with the flow of block diagram shown above is shown below,

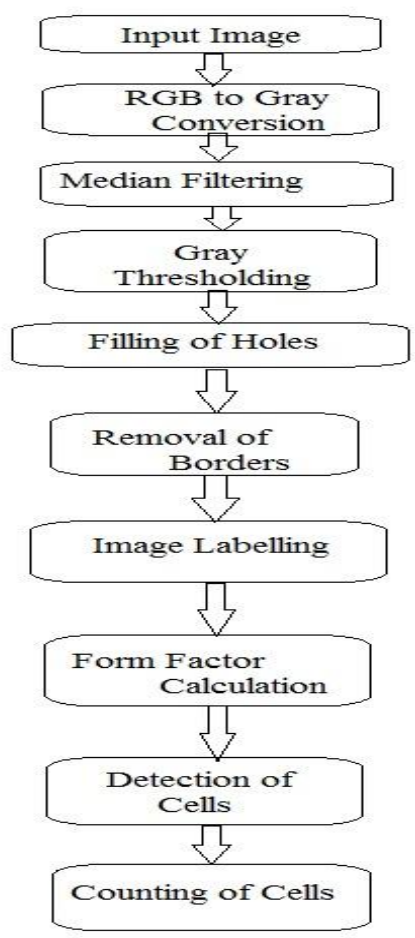

Fig-2: Flowchart for the proposed system

\subsection{Image Pre-processing}

Step 1: Input image

In this, when you click on pushbutton named input image, the current directory is opened, and from this you can select any patients folder to calculate that patients number of blood cells in his body. Like this, each patient's folder consists of five blood images with the medical report of that patient.

Step 2: RGB to Gray conversion

Image read in step-1 is in RGB format. But for post processing, this image is to be converted in to grayscale format. After converting image in to grayscale, salt $\mathrm{n}$ pepper noise is added in resultant image. Practically source of noise is thermal noise and artifacts i.e. noise added due to body movement.

Step 3: Median Filtering

Median filtering is used to remove noise which is added at the time of capturing the microscopic blood images. This noise can be the dust particles that are present on the blood slide while preparing the slides.

\subsection{Image Segmentation}

Step 1: Gray Thresholding

The gray thresholding function uses Otsu's method, which chooses the threshold to minimize the intra-class variance of the black and white pixels.

Step 2: Filling Holes

Holes presented in the binary image are filled so that the blood cells are segmented properly. 


\subsection{Image Post-processing}

Step 1: Removing Borders

The cells occupying the border contains less information and has to be removed to reduce the complexity. The segmented image is labeled.

Step 2: Image Labelling

Labels the connected objects. The objects can have a value of either 4 or8, where 4 specifies 4 -connected objects and 8 specifies 8-connectedobjects.

\subsection{Blood Cell Classification}

\subsubsection{Formula for RBC Count}

The following are some factors that are included in the formula of the manual counting of RBCs:

- The dilation of the blood for RBCs is $1 / 200$,

- assume that the total number of RBCs is some value ' $\mathrm{x}$ ',

- total number of squares is 80 ,

- the area of small squares is $1 / 400$ sq. $\mathrm{mm}$

- the depth of the counting chamber is $1 / 10$

- therefore, the volume of the small square is $1 / 4000$,

$$
\text { Total RBCs } / \mu 1=\frac{x \times 4000 \times 200}{80 \times 1 \times 1}
$$

\subsubsection{Formula for WBC Count}

The following are some factors that are included in the formula of the manual counting of WBCs:

- The dilation of the blood for WBCs is $1 / 20$,

- assume that the total number of WBCs is some value ' $y$ ',

- the depth of the counting chamber is $1 / 10$,

$$
\text { Total RBCs } / \mu 1=\frac{y \times 10 \times 20}{4 \times 1 \times 1}
$$

\subsection{Database}

For this work, we have taken blood images of 15 patients, and each patient 5 samples images are taken. This is because the blood cells are counted from 5 squares in the manual method. Hence, here we have used total 75 blood images which are of variable size with file format .jpg.

\section{EXPERIMENTATION}

The experiment is done on 15 patients. Each patients 5 images are taken as in manual counting method the cells are counted from 5 squares. After detecting the number of WBCs and RBCs, these counts are put in the above formula and the normalized counting is done to compare with the results of the pathology lab of the respective patients. The results are shown as below for 1 patient;
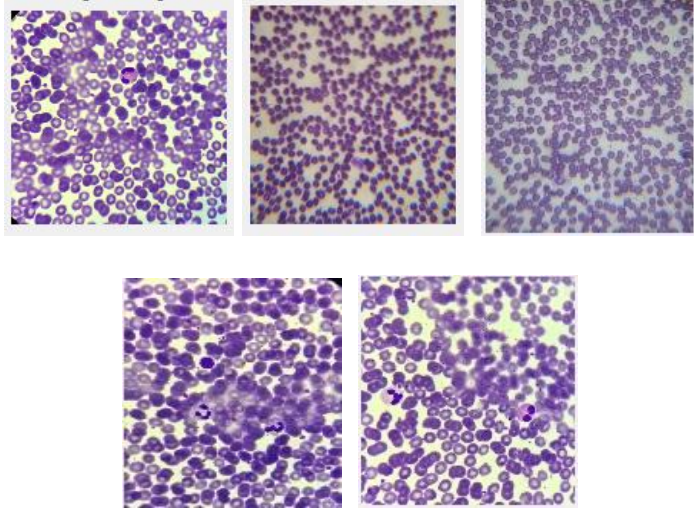

Fig-3: Input image
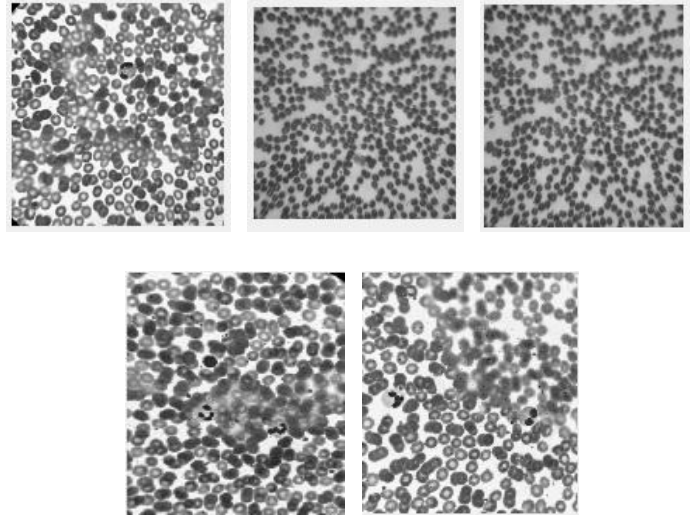

Fig-4: RGB to gray conversion

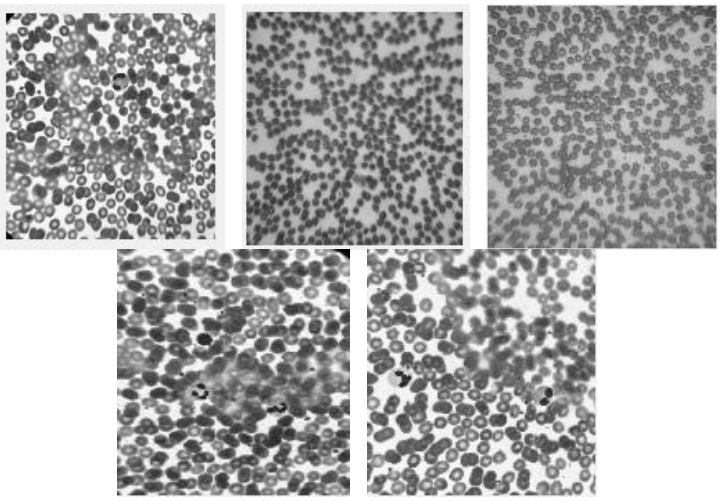

Fig-5: Filtered image
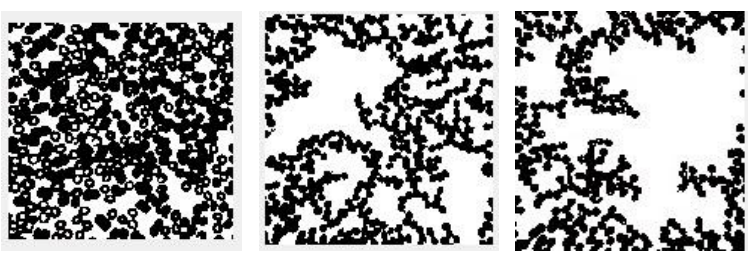


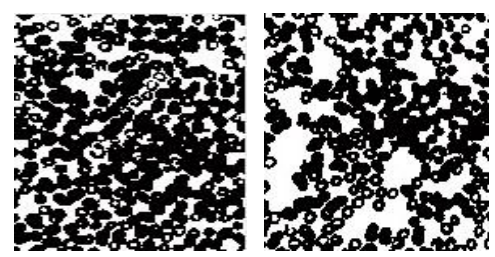

Fig-6: Gray Thresholding

After the gray thresholding step, the cells are been labeled and the total number of cells are counted, followed by the counting the number of WBCs with the help of the image labelling concept. These WBCs are subtracted from the total number of cells, which gives the RBCs count. These are the counts that I got; WBC is 157 and RBC is 359 and the report of the patient taken from the pathology lab is, WBC is $7.6 \times 10^{3}$ and $\mathrm{RBC}$ is $3.95 \times 10^{6}$. So, to compute with the pathological labs counts these are multiplied as WBCs are multiplied by 50 and RBCs are multiplied by 10000 . Then we get the counts as, WBC is equal to $7.85 \times 10^{3}$ and $\mathrm{RBC}$ is equal to $3.59 \times 10^{6}$. In this way these counts are compared with the reports taken of the particular patient from the pathology labs.

\subsection{Accuracy per Individual}

The accuracy is calculated for every patient by taking the difference of count of the experimental method and the automatic cell counts of pathological lab. The formula for calculating accuracy is given below:

$$
\text { Accuracy }=100 \% \text { - (greater count-smaller count }) \%
$$

This procedure is done for 15 patient's, WBCs and RBCs count. Using this formula, the accuracy that we got we got is $94.58 \%$.

\section{CONCLUSIONS}

If you calculate the blood cells using the manual method, the procedure takes nearly one hour to do so. Even now a days, if the automatic cell counter calculates irregular amount of cells in a patient's blood, the doctor count's with the manual method to analyze the count. Using the image processing method to calculate the blood cell count helps to do it faster within a fraction of few seconds. In this project, we have taken the images of 15 patients, each 5 images to calculate the WBCs and RBCs of each patient. The average time required and the average accuracy of the proposed system we got is 14.43 seconds and $94.58 \%$. This shows that the proposed system calculates the results fast and even more accurate than the manual method.

\section{ACKNOWLEDGEMENTS}

I am grateful to my guides Dr. G. S. Sable for providing me with invaluable guidance in this project.

\section{REFERENCES}

[1] A. Anand, V. K. Chhaniwal, N. R. Patel, B. Javidi, "Automatic Identifi Cation Of Malaria-Infected Rbc With Digital Holographic Microscopy Using Correlation Algorithms", IEEE Photonics Journal, Volume 4, Number 5, October 2012.

[2] Vincenzo Piuri, Fabio Scotti, "Morphological Classification of Blood Leucocytes By Microscope Images", IEEE International Conference On Computational Intelligence For Measurement Systems And Applications, Boston, Md, Usa, 14-16 July 2004.

[3] Pang-Yu Teng, Ahmet Murat Bagci, And Noam Alperin, "Automated Prescription Of An Optimal Imaging Plane For Measurement Of Cerebral Blood Flow By Phase Contrast Magnetic Resonance Imaging", IEEE Transactions on Biomedical Engineering, Vol. 58, No. 9, September 2011.

[4] Ela Ostrovsky, Udi Zelig, Irina Gusakova, Samuel Ariad, Shaul Mordechai, Ilana Nisky, And Joseph Kapilushnik, "Detection Of Cancer Using Advanced Computerized Analysis Of Infrared Spectra Of Peripheral Blood", IEEE Transactions On Biomedical Engineering, Vol. 60, No. 2, February 2013.

[5] Sanaullah Khan, Aamir Khan, Faisal Saleh Khattak, "An Accurate And Cost Effective Approach To Blood Cell Count", International Journal Of Computer Applications, Volume 50 - No.1, July 2012.

[6] Fauziah Kasmin, Anton Satria Prabuwono, Azizi Abdullah, "Detection of Leukemia In Human Blood Sample Based On Microscopic Images: A Study", Journal Of Theoretical And Applied Information Technology, Vol. 46 No.2, 31st December 2012.

[7] J. Poomcokrak And C. Neatpisarnvanit, "Red Blood Cells Extraction And Counting", The 3rd International Symposium On Biomedical Engineering, 2008.

[8] Lorenzo Putzu, And Cecilia Di Ruberto, "White Blood Cells Identification And Countingfrom Microscopic Blood Image", World Academy Of Science, Engineering And Technology, $73,2013$.

[9] Pallavi T. Suradkar, "Detection of Malarial Parasite In Blood Using Image Processing", International Journal Of Engineering And Innovative Technology (Ijeit) Volume 2, Issue 10, April 2013.

[10] Gaganjit Singh, Swarnalatha P., Tripathy B.K., Swetha Kakani, "Convex Hull Based Wbc Computation For Leukaemia Detection", International Journal Of Advanced Research In Electrical, Electronics And Instrumentation Engineering, Vol. 2, Issue 5, May 2013.

[11] Abdul Nasir, A. S., Mustafa, N., Mohd Nasir, N. F., "Application Of Thresholding Technique In Determining Ratio Of Blood Cells For Leukemia Detection", Proceedings Of The International Conference On Man-Machine Systems, 11 - 13 October 2009. 
[12] J. M. Sharif, M. F. Miswan, M. A. Ngadi, Md Sah Hj Salam, "Red Blood Cell Segmentation Using Masking And Watershed Algorithm: A Preliminary Study", International Conference On Biomedical Engineering, 27-28 February 2012.

\section{BIOGRAPHIES}

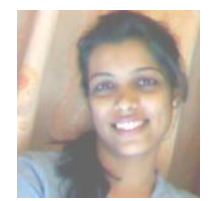

Pooja R. Patil, poojapatil1358@gmail.com. Student of M.E.(EC) 2ndYear, Savitribai Phule women's Engineering College, Aurangabad, Maharashtra, India. BE (E\&TC) from STB College of Engineering, Tuljapur, Maharashtra in 2011. She has total 1.5 years teaching experience. She is working as an Assistant professor in Aurangabad, Maharashtra, India. She has published 2 papers in international journal.

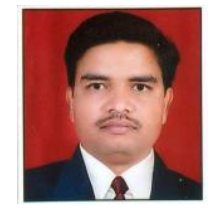

Dr.G.S.Sable, $\quad$ sable.eesa@gmail.com, Professor and Head of Electronics \& Telecommunication department at Savitribai Phule Women's Engineering College, Aurangabad, Maharashtra India. PhD from Dr.Babasaheb Marathwada University, Aurangabad, Maharashtra. M.E and B.E from J.N.E. College, Aurangabad. He has more than 40 publications to his credit and has been active in research and development. He has more than 14 years of teaching experience. He is a member of editorial advisory board of the different Journals. He is Authors of the book Microprocessor and Computer Organization for the second year CSE/IT Branch students and the member of the IEEE, ISTE, and IACSIT. He is Member of 32(6) a Malpractice Committee of Dr.Babasaheb Marathwada University, Aurangabad Maharashtra.

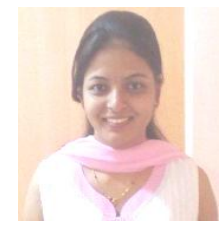

Gauri Anandgaonkar, gauri2569@gmail.com. Student of M.E.(EC) 2ndYear, Savitribai Phule women's Engineering College, Aurangabad, Maharashtra, India. BE (E\&TC) from PREC, Loni, Maharashtra in 2008. She has total 3.5 years teaching experience. She is working as an Assistant professor in Aurangabad, Maharashtra, India. She has published 2 papers in international journal. 